\title{
Archaeological cross-talk
}

\section{Richard Bradley}

In Search of the Indo-Europeans: Language, Archaeology and Myth. By J.P. Mallory. Thames \& Hudson: 1989. Pp.288. £24, \$29.95.

PREHISTORIANS make a virtue of a necessity. Deprived of written evidence, with all its latent biases, they have devoted enormous efforts to devising methods of talking about the past. The ideas may be adapted from those of anthropologists, of geographers and, sometimes, of historians, but the raw material for their studies comes from the purely physical byproducts of human behaviour. Only occasionally were they intended to convey information. Otherwise the work of archaeologists depends on understanding the relationship between human history and the peculiar character of the material that they investigate.

The methods of obtaining that evidence may be eminently practical, yet archaeologists cannot be innocent of theory once they come to interpret it. But theories are notoriously volatile. From an overriding concern with the chronology and distribution of objects, archaeology has come to investigate the changing character of society itself, and accounts that had long coloured popular understanding of the past have been found wanting. The most fundamental assumption to be questioned is that the more important changes in prehistoric Europe came about through the movement of peoples. Such an assumption implies a quite specific sequence of events, and sometimes this expectation has been confounded by scientific dating. In other cases archaeologists have been influenced by work in social anthropology and have come to understand how styles of object and systems of belief may be adopted over enormous distances in order to emphasize the position of local élites. The result is a much greater emphasis on local factors and on the whole process of social evolution.

The lack of written sources has given archaeologists a creative freedom, derided or envied by those who work in historical periods. Indeed, there are mediaevalists who believe that the archaeological record should be given priority over the more partial evidence of documents. This is a curious position, for by working with two different types of evidence historical archaeologists should be able to shed light on the strengths and weaknesses of the subject as a whole. For the prehistorian there is one comparable challenge to be faced. We know that by the dawn of written history societies as far apart as Ireland and Iran shared those closely related languages grouped together as 'Indo-European'. How and when did these relationships develop? It is here that archaeology must come to terms with a less familiar kind of evidence.

Prehistoric archaeology bears the imprint of one great man, Gordon Childe, who died over 30 years ago. Childe's achievement was to establish the basic grammar of the subject and to define the broad character of prehistoric Europe, using an approach influenced by his reading of Marx. His interpretation presupposed the movement of peoples and ideas from east to west, and from civilizations

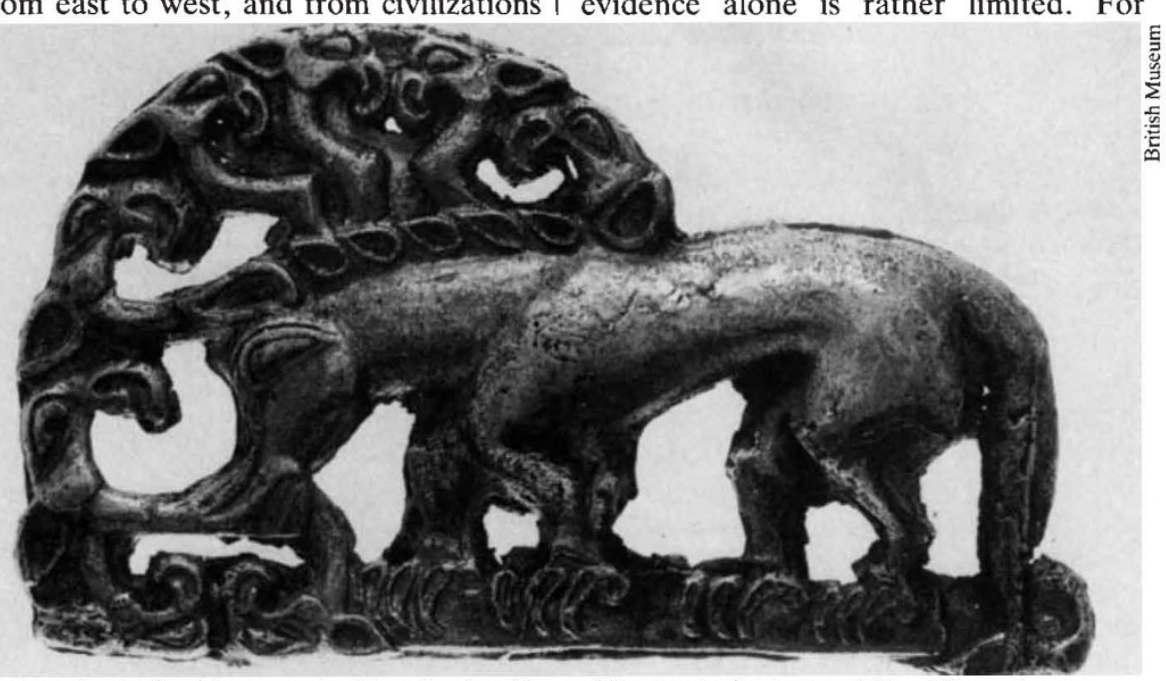

Archaeological evidence or just local colour? - a Siberian belt plaque, 5th-4th century BC.

into their barbarian peripheries. It is this part of his interpretation that has fallen victim to radiocarbon dating. But it is sometimes forgotten that Childe was also a linguist, profoundly influenced by his understanding of the geographical and chronological spread of ancient languages. One of his first books was entitled The Aryans (Keegan Paul, Trench, Trubner and Co., 1926), another name for the Indo-Europeans. It was precisely because the study of past languages became so deeply implicated in Nazi racial theory that Childe discontinued this side of his work. As a result of similar inhibitions, few people have confronted the relationship between archaeology and language.

Things are changing. Two years ago Colin Renfrew published a controversial study of this question (Archaeology and Language: The Puzzle of Indo-European Origins; Cape/Cambridge University Press, 1987); now Dr Mallory has produced an interpretation which differs fundamentally from that account. The issues have been keenly contested, with special numbers of leading journals being devoted to the theme (one protagonist in the debate has reviewed Renfrew's book, in increasingly heated terms, on at least three occasions). It is not hard to see why such a technical discussion should arouse so much interest, for it epitomizes the differences between two distinct attitudes to our study of the past.

For the 'traditionalists', among them Dr Mallory, the linguistic issues must take priority over the archaeological record. There are certain fundamental principles to do with the ways in which languages spread and the rates at which they change, and these cannot be challenged. Ultimately, the archaeological record must be consistent with those types of evidence: it cannot be decisive in itself and must accommodate the findings of the linguists. That means that we must postulate migrations for which the archaeological

Renfrew, on the other hand, archaeologists have gained sufficient confidence in handling their material that such a position is untenable. If linguistic theory does not measure up to the archaeological record, its own premises need to be reviewed. He identifies a fascinating failure of communication, in which both parties have deferred to one another - the linguists accommodating their analysis to what Renfrew considers an obsolete reading of the archaeology, and the archaeologists assuming that linguistic orthodoxies have to be taken at face value. The debate, then, is about the success or failure of archaeological interpretation itself, and Mallory and Renfrew are ranged on opposite sides.

The two historical narratives differ in fundamental ways. Mallory follows the traditional interpretation that the IndoEuropean languages spread through the migration of peoples from a homeland in the southern part of the Soviet Union and that this took place from the late fourth millennium BC onwards. The migrants were mainly pastoralists; they had a evidence alone is rather limited. For 
distinctive social system, echoed in our earliest written sources, and a series of religious beliefs that underpin the literature of many different parts of the world. For Renfrew, on the other hand, the archaeological evidence must be paramount, and he can find none to support a large-scale migration at that time. The main changes in the archaeological record are better explained in terms of local social developments. That is why he considers that the Indo-European dispersal must have taken place at a much earlier time. The only period in which such largescale expansion is seen in the archaeological record is with the spread of mixed farming around $6000 \mathrm{BC}$. Renfrew's IndoEuropeans originate in present-day Turkey. He develops a series of models to help us to understand how and why languages might have changed their distributions, but for Mallory these are problems that have already been solved by the linguist. For that reason, archaeology plays a subsidiary role in his discussion.

I have stressed the importance of the debate and the extent to which the participants disagree. That is because the point at issue seems to be the validity of the very methods used by archaeologists today. Were they right to reject the approach taken by Gordon Childe, with its emphasis on the movement of peoples? In the absence of other sources of information, such as the linguistic evidence discussed in great detail by Mallory, how can they decide between competing interpretations? It is the merit of this book that it states its position so clearly.

In Search of the Indo-Europeans lacks the rhetorical drive of Renfrew's more polemical statement, but in its place offers a detailed and fully illustrated account of the linguistic issues, and reviews the relevant archaeological evidence. It is well organized and well documented, but the reader can easily get lost in the archaeology. This is a pity because much of the material is unfamiliar and bears witness to Dr Mallory's extremely wide reading. On the other hand, it is the earlier chapters, where Mallory is concerned with broad issues, that work best on the page. His account of the linguistic evidence is actually more persuasive than his presentation of the archaeological sequence; indeed, some of the most telling arguments are to be found in the notes, and it is here that his differences with Renfrew come into sharpest focus.

Both books present a persuasive argument, but both cannot be correct. So how are we to proceed? If we concede the primacy of the linguistic analysis, the archaeological material is relegated to a supporting narrative, supplying local colour but insufficient to test the basic hypotheses. Mallory takes rather this line, rejecting the claims of theoretical archaeology to provide a self-sufficient inter-

pretation of the past. If recent archaeological research is correct, however, the linguists must think again.

Can we find other sources of information that may help to break the deadlock? Perhaps we should look more closely at research on the distribution of human blood groups, and even at the evidence of population change provided by modern physical anthropology. We may be inhibited by the ways in which such studies have been turned to political ends, but there seems to be little alternative. An impor-

\section{In those days}

\section{Warwick Bray}

The Pastmasters: Eleven Modern Pioneers of Archaeology. Edited by Glyn Daniel and Christopher Chippindale. Thames \& Hudson: 1989. Pp.176. £18, $\$ 22.50$.

THE essays in this book were commissioned by Glyn Daniel and published separately in Antiquity, all but one of them between 1980 and 1989. Eminent archaeologists were asked to look back over their careers, to summarize what they thought were their achievements (and sometimes failures), and to discuss what personal and intellectual influences had moulded their lives and personalities.

The chosen few, all men, are Childe, Piggott, Phillips, Hawkes, Seton Lloyd, Braidwood, Willey, C. J. Becker, De Laet, Desmond Clark and D.J. Mulvaney. There is a touch of cronyism in the selection; these are people Glyn Daniel knew and liked, but each of them is a figure of real substance. Some - Clark in Africa, Mulvaney in Australia - span the entire history of archaeology in their respective areas. Some are field men, others synthesizers and teachers, but all of them, through a mixture of scholarship, administration and patronage, helped to form archaeology as it is today. The Americas are under-represented, but it is good to see the intellectual contribution of Scandinavia and the Low Countries receiving due recognition.

Each author has produced what was required, a sort of anecdotal curriculum vitae rather than a critique of archaeology as it is now. Some of the stories confirm the popular impression of the protagonists. The shocking state of Gordon Childe's trousers after 25 years of hard wear will surprise nobody, nor will the pedigree of Stuart Piggott (a chalkland hobbit cruelly uprooted to Scotland), whose family "had been around in Marcham, Hatford and West Challow since the early seventeenth century". Less predictably, Willey was a would-be track star, and Clark believes the teamwork of a tant debate is taking place, immeasurably sharpened by the clarity with which the rival positions have been expressed, but that discussion threatens to take on a hermetic quality and must be broadened. In the meantime I have every praise for $\mathrm{Dr}$ Mallory in expounding what may seem an unfashionable view, and for doing so with such lucidity, balance and good humour.

Richard Bradley is Professor in the Department of Archaeology, University of Reading, Whiteknights, Reading RG6 2AH, UK

rowing eight is ideal training for teamwork in the field. These trivia are entertaining, but they also help to reveal the personalities behind the publications (and the fate of scientific programmes, individual careers and university departments has as often been decided by personality as by reason and justice). So it matters that Christopher Hawkes, in his otherwise solemn essay, wants us to know that he danced an exhibition tango at the Mediterranean Congress in 1950. My reaction to this is summed up by van Giffen's remark at the time: "I did not know you were such a man".

The papers gain from being printed together and, cumulatively, they give an inside impression of the archaeological world at the critical time when it was first becoming professional. It is a picture I recognize from my own student years. The world was smaller and quieter then. There was less to know; everybody knew everyone else; whole new continents were opening up to archaeology, and radiocarbon dating was beginning to sort out the muddles over chronology. There were pressures, too, and occasional unpleasantnesses, but these are discreetly glossed over in this rather bland book.

Members of the 'Don't trust anyone over $30^{\prime}$ generation often complain that their elders were naive in matters of theory, and far too preoccupied with digging, dating and writing culture history. These people should read the eightpage contribution by Gordon Childe, written in 1958 . He was wrong about many things, but he had absorbed the works of Spengler and Hegel, Malinowski and Durkheim, as well as Morgan and Marx. He drew upon the philosophy of science (and of history), employed ethnographic analogies, worried about modes of production and the nature of culture, and sought laws of human behaviour analogous to those of physics and chemistry. Childe, and several of the others in the book, were as innovative in their time as any of today's Young Turks, and it does no harm to remember that once in a while.

Warwick Bray is Reader in Latin American Archaeology at the Institute of Archaeology. University College, London WC1H OPY, UK. 